\title{
INFLUÊNCIA DAS VARIÁVEIS SUPERSATURAÇÃO E POPULAÇÃO DE SEMENTES NO RENDIMENTO DE ÁCIDO CÍTRICO NA ETAPA DE CRISTALIZAÇÃO
}

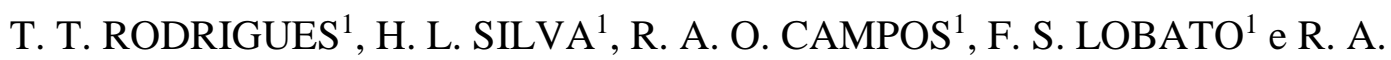 \\ MALAGONI $^{1}$ \\ ${ }^{1}$ Universidade Federal de Uberlândia, Faculdade de Engenharia Química \\ E-mail para contato: malagoni@ufu.br
}

\begin{abstract}
RESUMO - O ácido cítrico é uma substância de alta relevância e aplicabilidade na indústria química, de alimentos e farmacêutica. Ele é encontrado em diversas frutas cítricas, sendo um metabólito comum em animais e plantas. A cristalização é uma das etapas finais da produção do ácido cítrico, em que se produz cristais de elevada pureza. O objetivo deste trabalho é estudar a influência das variáveis supersaturação e população de sementes no rendimento do ácido cítrico na etapa de cristalização em um processo a temperatura constante, a $55^{\circ} \mathrm{C}$. Os resultados obtidos foram comparados com dados da literatura em que se realizou a cristalização por resfriamento controlado em uma faixa de temperatura de $50^{\circ} \mathrm{C}$ a $40^{\circ} \mathrm{C}$. Concluiu-se que ambas as variáveis interferem no tamanho e na qualidade dos cristais e que o método por resfriamento controlado tem maior rendimento.
\end{abstract}

\section{INTRODUÇÃO}

$\mathrm{O}$ ácido cítrico ou ácido 2-hidróxido-1,2,3-propanotricarboxílico $\left(\mathrm{C}_{6} \mathrm{H}_{8} \mathrm{O}_{7}\right)$ é um sólido branco cristalino e inodoro com densidade $1,665 \mathrm{~g} \cdot \mathrm{cm}^{-3}$ e massa molar $192,13 \mathrm{~g} \cdot \mathrm{mol}^{-1}$. Além disso, tem boa solubilidade em água e moderada em etanol (Kirk et al., 1979).

Esse composto é considerado um ácido orgânico fraco encontrado comumente nos citrinos como limão, tangerina e laranja. Algumas de suas aplicações importantes são o controle de crescimento microbiano, o uso como acidulante, a redução de $\mathrm{pH}$ em soluções de interesse, a ação quelante e o uso como aromatizante. Industrialmente, sua aplicabilidade se estende à produção de fármacos, alimentos e bebidas (The Columbia Encyclopedia, 2001). Aproximadamente $70 \%$ do ácido cítrico produzido é utilizado na indústria alimentícia e de bebidas, $12 \%$ na farmacêutica e $18 \%$ é destinado a outros usos industriais (Leonel e Cerada, 1995).

Segundo Bessa (2001), na maioria dos processos industriais, o ácido cítrico é produzido a partir da fermentação da sacarose pelo fungo Aspergillus niger e, a comercialização, acontece em duas formas: anidra e monohidratada, sendo a temperatura de transição entre essas fases $36,6^{\circ} \mathrm{C}$. Acima desta temperatura, cristaliza-se a forma anidra e abaixo, a forma monohidratada.

De acordo com Mullin (2001), a cristalização fornece um produto com elevado grau de pureza, baixo nível de contaminação, cristais de boa aparência, de fácil manuseio e estocagem. 
Diante do exposto, o objetivo deste trabalho é estudar a influência das variáveis supersaturação e população de sementes no rendimento de ácido cítrico no processo de cristalização a $55^{\circ} \mathrm{C}$.

\section{MATERIAL E MÉTODOS}

\subsection{Material}

- Cristalizador encamisado de vidro borossilicato;

- Agitador mecânico (Gehaka, modelo AM-20);

- Agitador com propulsor do tipo hélice naval;

- Indicador de temperatura acoplado ao termopar (Full Gauge, modelo TIC-17RGTi);

- Banho termostatizado (Tecnal, modelo TE-184);

- Conjunto de peneiras da marca Bertel constituído por peneiras Tyler 12, 14, 16, 20 , 48 e o prato de fundo;

- Vibrador de peneiras (Produtest);

- Balança analítica (Gehaka, AG-200);

- Sementes de ácido cítrico (Cargill, pureza: 99,5\%);

- Água destilada e deionizada.

\subsection{Métodos}

As sementes utilizadas nos ensaios de cristalização foram obtidas por peneiramento usando as peneiras Tyler 12, 14, 16, 20 e o prato de fundo, conforme procedimento de Malagoni (2010) e Teixeira (2011). Na obtenção das sementes, $100 \mathrm{~g}$ de ácido cítrico foram peneiradas durante 20 minutos, sendo os cristais retidos na peneira de malha Tyler 20 usados como sementes.

A solubilidade do ácido cítrico anidro em água foi determinada utilizando a correlação de Oliveira et al. (2013) em termos da fração molar (x) de ácido cítrico, válida para a faixa de temperatura de 20 a $60^{\circ} \mathrm{C}$, conforme apresentado na Equação (1), sendo $T$ a temperatura em kelvin.

$$
x=\exp \left(2,053-\frac{1204,74}{T}\right)
$$

Posteriormente, utilizou-se uma base de cálculo de $100 \mathrm{~g}$ de água $\left(m_{2}\right)$ e com a Equação (2) foi encontrado a massa de ácido cítrico $\left(m_{1}\right)$, podendo se calcular a concentração de equilíbrio $\left(C^{*}\right)$ em $\mathrm{g} / 100$ de água.

$$
x=\frac{m_{1} / M_{1}}{\left(m_{1} / M_{1}\right)+\left(m_{2} / M_{2}\right)}
$$

A concentração na condição de supersaturação $(C)$ é calculada pela Equação (3), a partir do grau de supersaturação $(S)$ desejado e da concentração de equilíbrio ou na condição de saturação $\left(C^{*}\right)$. 


$$
S=\frac{C}{C^{*}}
$$

Com o valor da concentração na supersaturação, quantificam-se as massas de ácido cítrico e água necessárias no preparo da solução supersaturada a $55^{\circ} \mathrm{C}$. As massas de ácido cítrico e água foram quantificadas utilizando uma balança analítica de precisão $\pm 0,0001 \mathrm{~g}$, sendo na sequência, adicionadas ao cristalizador encamisado. A solução com um volume de $291 \mathrm{~mL}$ foi preparada sob agitação de $198 \mathrm{rpm}$ a $75^{\circ} \mathrm{C}$ até que ocorresse a dissolução total do soluto. Posteriormente, o set point do banho termostatizado foi ajustado de forma que a solução no cristalizador permanecesse a $55^{\circ} \mathrm{C}$, obtendo-se o grau de supersaturação desejado.

As sementes de ácido cítrico passaram por um processo de cura, ou seja, foram lavadas com uma solução quase saturada a $25^{\circ} \mathrm{C}$ e, posteriormente, elas foram adicionadas ao cristalizador. O agitador foi acionado a uma rotação de $198 \mathrm{rpm}$, mantendo-se a temperatura de cristalização constante. As amostras foram retiradas a cada 16 minutos, totalizando 10 amostras por experimento. As amostras foram retiradas do cristalizador utilizando uma peneira Tyler 48 pré-aquecida a $60^{\circ} \mathrm{C}$. Os cristais foram lavados utilizando $5 \mathrm{~mL}$ de uma solução de clorofórmio $98 \%$ e então levados a estufa a $60^{\circ} \mathrm{C}$ por 24 horas.

O rendimento (y) do processo de cristalização foi calculado através da Equação (4), sendo $\left(m_{f}\right)$ a massa final de ácido cítrico medida após 24 horas de secagem e $\left(m_{s}\right)$ a massa das sementes.

$$
y(\%)=\left(\frac{m_{f}}{m_{s}}-1\right) \times 100
$$

Os resultados experimentais de rendimento de ácido cítrico na etapa de cristalização foram obtidos a partir de um Planejamento Composto Central (PCC) constituído por 11 experimentos e três réplicas no ponto central, no qual se analisou as variáveis: grau de supersaturação $\left(x_{1}\right)$ e a população de sementes $\left(x_{2}\right)$.

\section{RESULTADOS E DISCUSSÃO}

A Tabela 1 apresenta os resultados experimentais de rendimento obtidos neste trabalho a partir do PCC. Observa-se que o maior rendimento foi de 277,32\%, para o nível superior de supersaturação (+1) e para o nível inferior de população de sementes (-1), ou seja, em uma condição de menor competitividade, os cristais crescem mais já que estão em um meio com maior disponibilidade de soluto. O menor rendimento foi de $143,28 \%$, o que já era esperado, pois estava se operando no nível superior de sementes (+1) e no nível inferior de supersaturação (-1), muitas sementes em um meio com menor disponibilidade de soluto para promover a cristalização. Considerando os 11 experimentos verifica-se que o rendimento médio foi de $198,06 \%$. 
Tabela 1 - Matriz do PCC com a resposta rendimento.

\begin{tabular}{cccccc}
\hline Experimento & $x_{1}$ & $\begin{array}{c}\text { Grau de } \\
\text { Supersaturação } \\
(-)\end{array}$ & $x_{2}$ & $\begin{array}{c}\text { Quantidade } \\
\text { de sementes } \\
(\mathrm{g})\end{array}$ & $\begin{array}{c}\text { Rendimento } \\
(\%)\end{array}$ \\
\hline 1 & $-1,00$ & 1,10 & $-1,00$ & 23,80 & 233,55 \\
2 & $-1,00$ & 1,10 & 1,00 & 37,40 & 143,28 \\
3 & 1,00 & 1,20 & $-1,00$ & 23,80 & 277,32 \\
4 & 1,00 & 1,20 & 1,00 & 37,40 & 169,54 \\
5 & $-1,41$ & 1,08 & 0,00 & 30,60 & 173,92 \\
6 & 1,41 & 1,22 & 0,00 & 30,60 & 270,25 \\
7 & 0,00 & 1,15 & $-1,41$ & 20,98 & 196,24 \\
8 & 0,00 & 1,15 & 1,41 & 40,21 & 159,16 \\
9 & 0,00 & 1,15 & 0,00 & 30,60 & 186,46 \\
10 & 0,00 & 1,15 & 0,00 & 30,60 & 181,16 \\
11 & 0,00 & 1,15 & 0,00 & 30,60 & 187,73 \\
\hline
\end{tabular}

A Tabela 2 traz os resultados de Castro (2016), em que os experimentos foram realizados utilizando também um PCC, com os mesmos valores de supersaturação e quantidade de sementes, entretanto, com o processo de cristalização ocorrendo por resfriamento, em que se variou a temperatura de 50 a $40^{\circ} \mathrm{C}$.

Tabela 2 - Resultados de cristalização de Castro (2016).

\begin{tabular}{cccccc}
\hline Experimento & $x_{1}$ & $\begin{array}{c}\text { Grau de } \\
\text { Supersaturação } \\
(-)\end{array}$ & $x_{2}$ & $\begin{array}{c}\text { Quantidade } \\
\text { de sementes } \\
(\mathrm{g})\end{array}$ & $\begin{array}{c}\text { Rendimento } \\
(\%)\end{array}$ \\
\hline 1 & $-1,00$ & 1,10 & $-1,00$ & 23,80 & 195,11 \\
2 & $-1,00$ & 1,10 & 1,00 & 37,40 & 162,65 \\
3 & 1,00 & 1,20 & $-1,00$ & 23,80 & 272,62 \\
4 & 1,00 & 1,20 & 1,00 & 37,40 & 193,29 \\
5 & $-1,41$ & 1,08 & 0,00 & 30,60 & 153,85 \\
6 & 1,41 & 1,22 & 0,00 & 30,60 & 262,86 \\
7 & 0,00 & 1,15 & $-1,41$ & 20,98 & 256,78 \\
8 & 0,00 & 1,15 & 1,41 & 40,21 & 162,95 \\
9 & 0,00 & 1,15 & 0,00 & 30,60 & 196,34 \\
10 & 0,00 & 1,15 & 0,00 & 30,60 & 202,33 \\
11 & 0,00 & 1,15 & 0,00 & 30,60 & 194,68 \\
\hline
\end{tabular}

Pela Tabela 2, a partir dos valores de rendimento apresentados, determina-se o valor médio de rendimento, igual a $204,86 \%$, ou seja, um pouco acima do valor médio de $198,06 \%$ obtido em experimentos de cristalização a temperatura constante. Nota-se que em processos de cristalização por resfriamento controlado, a supersaturação mantém-se constante durante todo o experimento, proporcionado maior rendimento no processo de cristalização.

No estudo da cristalização do ácido cítrico, Teixeira (2011) obteve um rendimento máximo de 165,31\% e Malagoni (2010) 157\%, ambos em processos de cristalização em leito 
vibrado. Dessa forma, nota-se que em processo de cristalização realizado em cristalizador batelada agitado os valores de rendimento foram maiores.

\section{CONCLUSÃO}

Os resultados experimentais obtidos foram satisfatórios por estarem em consonância com o que era esperado de acordo com a teoria. Ambas as variáveis estudadas apresentaram efeito sobre o rendimento do ácido cítrico no processo de cristalização, alcançando níveis de rendimento de até $277,32 \%$, sendo maiores que os resultados dispostos na literatura para processos de cristalização em leito vibrado. De acordo com os resultados, o melhor rendimento de ácido cítrico aconteceu para um grau de supersaturação elevado e baixa população de sementes.

Comparando o rendimento dos experimentos realizados à temperatura constante com os experimentos em temperatura variável, nota-se que quando ocorre um resfriamento controlado, o rendimento é superior. Este ponto indica que o rendimento do ácido cítrico sofre a influência da temperatura e a cristalização é mais efetiva quando há uma variação controlada da temperatura.

\section{NOMENCLATURA}

Símbolo
$C$
$C^{*}$
$m_{1}$
$M_{1}$
$m_{2}$
$M_{2}$
$m_{f}$
$m_{s}$
$S$
$T$
$x_{1}$
$x_{2}$

\section{Descrição}

Concentração do sistema

Concentração de saturação na temperatura do sistema

Massa de ácido cítrico

Massa molecular do ácido cítrico

Massa de água

Massa molecular da água

Massa final do ácido cítrico

Massa de sementes

Grau de supersaturação

Temperatura de operação

Variável codificada do grau de supersaturação

Variável codificada da população de semente
Unidade [g·g de água ${ }^{-1}$ ] $\left[\mathrm{g} \cdot \mathrm{g}\right.$ de água $\left.{ }^{-1}\right]$ $[\mathrm{g}]$
$\left[\mathrm{g} \cdot \mathrm{mol}^{-1}\right]$
$[\mathrm{g}]$
$\left[\mathrm{g} \cdot \mathrm{mol}^{-1}\right]$
$[\mathrm{g}]$
$[\mathrm{g}]$
$[-]$
$[\mathrm{K}]$
$[-]$
$[-]$

\section{REFERÊNCIAS}

BESSA, J. A. de A. Cristalização de ácido cítrico - influência da agitação com paleta rotativa e com discos vibrados. 2001. 93 f. Dissertação (Mestrado em Engenharia Química) Universidade Federal de Uberlândia, Uberlândia, 2001. 


\section{Congresso Brasileiro de Engenharia \\ Química em Iniciação Científica \\ UFSCar - São Carlos - SP

CASTRO, C. C. Estudo numérico-experimental da etapa de cristalização do ácido cítrico. 2016. 127 f. Dissertação (Mestrado em Engenharia Química) - Faculdade de Engenharia Química, Universidade Federal de Uberlândia, Uberlândia, 2016.

KIRK, R. E.; OTHMER, D. F.; GRAYSON, M.; ECKROTH, D. Kirk-othmer encyclopedia of chemical technology. V. 6. 1. ed. New York: John Wiley \& Sons, 1979. 869 p.

LEONEL, M.; CERADA, M. P. Manipueira como substrato na biossíntese de ácido cítrico por Aspergillus niger. Science Agricultural, 52, 2, p. 299-304, 1995.

MALAGONI, R.A. Cristalização de ácido cítrico em leito vibrado. 2010. 297 f. Tese (Doutorado em Engenharia Química) - Universidade Federal de Uberlândia, Programa Pós-Graduação em Engenharia Química, Uberlândia, 2010.

MULLIN, J. W. Crystallization. 4. ed. Oxford: Butterworth-Heinemann, 2001. 594 p.

OLIVEIRA, M. L. N.; MALAGONI, R. A.; FRANCO, M. R. Solubility of citric acid in water,etanol, n-propanol and in mixtures of etanol+water. Fluid Phase Equilibria, v. 352, p. $110-113,2013$

TEIXEIRA, G. A. Estudo da produtividade no processo de cristalização de ácido cítrico em leito vibrado. 2011. 144 f. Dissertação (Mestrado em Engenharia Química) Universidade Federal de Uberlândia, Uberlândia, 2011.

THE COLUMBIA ENCYCLOPEDIA. Encyclopedia. 6.ed. New York: Columbia University Press, 2001. 3200 p.

\section{AGRADECIMENTOS}

Os autores agradecem ao CNPq pela bolsa de Iniciação Científica (PIBIC CNPQ2016ENG011), a PROGRAD/UFU pela bolsa de Apoio aos Laboratórios de Ensino (2016PBGPROJETO223) e à Faculdade de Engenharia Química da Universidade Federal de Uberlândia pela estrutura física disponibilizada para o desenvolvimento desta pesquisa no Laboratório de Cristalização. 